\title{
Consumer Ethnocentrism vs. Intercultural Competence as Moderators in Intercultural Service Encounters \\ INTRODUCTION
}

Intercultural encounters involve interactions between customers and employees from different cultural backgrounds (Stauss and Mang, 1999). Due to recent advances in globalization, there is a rapid rise in international travel and migration, which in turn has resulted in a dramatic increase in the frequency of intercultural service encounters (Etgar and Fuchs, 2011; Teng, 2011; Wang and Mattila, 2010). Therefore, it is becoming quite important for international service firms to acknowledge the importance of intercultural service encounters and to understand the unique challenges posed by the differences in the perceptions, expectations and evaluations of their customers and employees shaped by their diverse cultures (Sharma et al., 2009, 2012).

Prior research on intercultural service encounters explores the roles of culture shock (Stauss and Mang, 1999), perceived discrimination (Barker and Härtel, 2004), behavioral biases in the employees' responses (Martin and Adams, 1999; McCormick and Kinloch, 1986), crosscultural interaction comfort (Paswan and Ganesh, 2005), consumer ethnocentrism (Javalgi and Martin, 2007; Sharma et al., 2005; Ueltschy et al., 2007), ethnic/cultural dissimilarity (Etgar and Fuchs, 2011), reactions to service failure and recovery (de Matos et al., 2011; Wang and Mattila, 2011), perceived cultural distance, intercultural competence and inter-role congruence (Sharma et al., 2009, 2012). However, despite growing research interest in this important area in services marketing, there are still many research gaps and unanswered questions.

One of the most important research gaps in this area is the lack of consensus on the role of perceived cultural distance in intercultural service encounters. Some studies show a negative effect on interaction comfort (Ali-Sulaiti and Baker, 1998; Harrison-Walker, 1995; Hopkins et al., 2005; Kulik and Holbrook, 2000) whereas others found a positive effect (Stauss and Mang, 
1999; Warden et al., 2003; Weiermair, 2000). Stauss and Mang (1999) explain the positive effect of perceived cultural distance by arguing that customers may attribute cultural differences for the failure in intercultural service encounters and it may make them more tolerant towards service providers with other ethnicity or nationality. However, it is not clear if this is true for all kinds of customers or would some customer be more prone to such attributions compared to others.

We argue that an important reason for such mixed evidence could be that most of these studies explored the main effects of perceived cultural distance or ethnicity/nationality of the service provider on customer satisfaction or perceived service quality without accounting for the role of potential moderators such as intercultural competence (Sharma et al., 2009, 2012) and consumer ethnocentrism (Sharma et al., 2005; Thelen et al., 2011). Moreover, most of these studies focused on service failure and ignored successful service encounters, which may have also influenced their results by not providing a complete picture of how customers perceive and evaluate their experience in an intercultural service encounter.

We address the above gap with a comprehensive conceptual framework incorporating both service outcome (failure vs. success) and perceived cultural distance (low vs. high) as antecedents to interaction comfort and perceived service quality, which in turn lead to customer satisfaction. Our model also includes consumer ethnocentrism and intercultural competence as moderators with contrasting effects on the influence of service outcome and perceived cultural distance on interaction comfort and perceived service quality respectively. We develop ten specific hypotheses on the relationships among all these constructs and report our results from an experimental study that supports all our hypotheses. Finally, we discuss the conceptual contribution and managerial implications of our findings, along with the limitations of our study and some directions for future research. 


\section{CONCEPTUAL FRAMEWORK AND HYPOTHESES}

\section{Perceived Cultural Distance (PCD)}

Cultural distance is defined as the extent to which cultures are different from each other in terms of broad cultural elements, including ethnicity, language, social structure, religion and values (Triandis, 1994). Based on this definition, Sharma et al. (2009) conceptualize perceived cultural distance as the extent to which people from one culture perceive people from other cultures to be different from them in terms of their ethnicity, nationality, language, values and customs. According to this conceptual definition, a lower perceived cultural distance between people would facilitate their inter-personal communication and understanding of each other as well as improve the quality of their interaction and its perceived outcomes. One would expect the opposite results for people with greater perceived cultural distance.

However, prior research shows mixed findings about the influence of perceived cultural distance in intercultural service encounters. For example, many studies show that customers prefer being served by employees with the same nationality (Ali-Sulaiti and Baker, 1998; Harrison-Walker, 1995) or the same race as them (Kulik and Holbrook, 2000), possibly due to their smaller perceived cultural distance, which may lead to greater trust and familiarity. In fact, customers are also shown to use salient cultural identity cues to self-select service providers with similar cultural characteristics (Hopkins et al., 2005).

In contrast, others show that perceived cultural distance has an unexpected positive influence on the satisfaction of Japanese, American and German passengers of a German airline in intercultural service encounters (Stauss and Mang, 1999), which they explain by suggesting that customers may adjust their expectations downwards if they attribute the service failure to the cultural differences. Similar findings are reported by Weiermair (2000) and his colleagues in 
Austria, showing that customers are less demanding and more tolerant in their interactions with culturally distant service providers. Warden, Liu and Huang (2003) show similar results with consumers in Taiwan wherein customers report higher satisfaction in intercultural service encounters possibly due to their greater acceptance of recovery strategies in such settings. Finally, Sharma et al. (2012) also report similar results with restaurant customers in Hong Kong showing an unexpected positive impact of perceived cultural distance on their interaction comfort.

Based on the above, it is clear that we need more research in this area to further deepen our understanding and possibly identify new variables and relationships to explain these mixed findings. In addition to the above mixed evidence about the influence of perceived cultural distance, most prior studies focus on cases of service failure and ignore successful service encounters. Hence, it is not clear if perceived cultural distance has a similar impact on customer perceptions and evaluations if the service outcome is a failure or a success.

\section{Interaction Comfort (IC)}

Interaction comfort is a psychological state experience by customers during a service encounter, wherein they feel calm and comfortable rather than anxious, worried or insecure (Spake et al., 2003). Interaction comfort has a positive effect on important customer outcomes such as trust, commitment, perceived service quality and satisfaction with the service provider (Dabholkar et al., 2000) and as suggested by Sharma et al. (2009) people generally feel uncomfortable when interacting with those from other cultures. Hence, it is important to study the role of interaction comfort in intercultural service encounters.

Sharma et al. (2009) also propose that cultural similarity between customers and employees in terms of language, values, and norms helps them communicate effectively, feel more comfortable with each other and experience greater customer satisfaction. In fact, social 
identity theory (Tajfel et al., 1971) also suggests that lower perceived cultural distance may help customers and employees identify each other as members of the same in-group and hence be more tolerant with each other. In general, greater perceived cultural distance makes people uncomfortable in cross-cultural interactions (Hopkins et al., 2005; Paswan and Ganesh, 2005) and this lack of interaction comfort may have an adverse impact on the customers' perceptions and evaluations of their service experience. Therefore, we hypothesize as follows:

H1: Perceived cultural distance has a negative effect on interaction comfort.

\section{Service Outcome (Failure vs. Success)}

Prior research on intercultural service encounters focuses mostly on service failures (e.g., Sharma et al., 2012; Stauss and Mang, 1999; Wang and Mattila, 2011; Warden et al., 2003; Weiermair, 2000), hence it is not clear if and how their findings would apply to successful intercultural service encounters. In this context, it is argued that customers may not pay close attention in successful service encounters thinking of these as foregone conclusions (Oliver et al., 1997); whereas customers may experience psychological discomfort in case of service failures and look for its causes in an attempt to restore their psychological equilibrium (Laufer, 2002).

Based on the above, we argue that in successful intercultural service encounters, customers are likely to experience greater level of interaction comfort because either they may not perceive the cultural distance with the employees in such situations or not allow the perceived cultural distance to affect their judgments about service quality and their satisfaction level. In contrast, under service failures, customers would experience lower level of interaction comfort because of their poor service experience. Hence, we hypothesize as follows:

H2: Service failure (success) leads to lower (higher) interaction comfort. 


\section{Perceived Service Quality (PSQ)}

Perceived service quality is a well-established construct, defined as a global judgment or attitude based on customers' beliefs about their service experience (Parasuraman et al., 1988). Service quality has a positive impact on customer satisfaction and other behavioral outcomes such as purchase intentions, repeat purchase and positive word-of-mouth (Zeithaml et al., 1996). Customers generally perceive lower level of service quality in intercultural service encounters although there is mixed evidence about its influence on other customer outcomes (Ali-Sulaiti and Baker, 1998; Harrison-Walker, 1995; Hopkins et al., 2005; Kulik and Holbrook, 2000; Stauss and Mang, 1999; Warden et al., 2003; Weiermair, 2000). Hence, there is a need to systematically study the factors influencing perceived service quality and its impact on customer satisfaction, in intercultural service encounters.

In this context, Sharma et al. (2012) argue that perceived cultural distance between customers and employees can amplify the differences in their perceptions about each other's role and performance as well as overall service quality. We argue that perceived cultural distance may not only affect customer perceptions but also increase their expectations from culturally distant service employees and hence make them more sensitive to the quality of service provided by these employees. Moreover, successful service encounters are likely to be associated with greater perceived service quality compared to service failures. Hence, we hypothesize as follows:

H3: Perceived cultural distance has a negative effect on perceived service quality.

H4: Service failure (success) leads to lower (higher) perceived service quality.

\section{Satisfaction (SAT)}

Customer satisfaction is defined as an emotional state experienced in response to an evaluation of their experience in a service encounter (Oliver, 1997) and it is influenced by factors 
such as, perceived employee effort (Mohr and Bitner, 1995) and employee performance during a service encounter (Dolen et al., 2004; Schneider and Bowen, 1985). Customer satisfaction drives other important outcomes such as repeat purchase and loyalty (Seiders et al., 2005). Customers generally report lower level of satisfaction in intercultural service encounters because of the perceived gap in the ability of the service providers in understanding and meeting customer expectations (Etgar and Fuchs, 2011; Sharma et al., 2012; Ueltschy et al., 2007).

Prior studies on intercultural service encounters show a positive effect of interaction comfort on service evaluation (Paswan and Ganesh, 2005) and perceived service level on customer satisfaction (e.g., Sharma et al., 2012). However, there is little research on the role of interaction comfort and perceived service quality in the process by which customers form their satisfaction judgments in intercultural service encounters. We argue that both interaction comfort and service quality are necessary for customer satisfaction. Hence, the following hypotheses:

H5: Interaction comfort has a positive effect on customer satisfaction.

H6: Perceived service quality has a positive effect on customer satisfaction.

Next, we describe two relevant variables, consumer ethnocentrism and intercultural competence, which play important roles in the process by which customers evaluate their experience in intercultural service encounters. Prior research shows a positive influence of intercultural competence on customer perceptions and evaluation of service providers from other cultures (e.g., Sharma et al. 2009, 2012). In contrast, consumer ethnocentrism has a negative effect on the evaluation of foreign products and services coupled with a positive effect on the preference for domestic products and services (Ali-Sulaiti and Baker, 1998; Harrison-Walker, 1995; Sharma et al., 2005; Sharma et al., 1995). However, there is no research that combines 
both these constructs in a common framework and examines their direct and indirect effects on key customer outcomes such as interaction comfort, service quality and customer satisfaction.

\section{Intercultural Competence (ICC):}

Intercultural competence is defined as the ability to think and act in appropriate ways when interacting with people from other cultures (Friedman and Antal, 2005). People with higher intercultural competence show more respect and empathy for those from other cultures and interact with them in an unbiased manner without any visible discomfort (Lustig and Koester, 2006). People with higher intercultural competence also possess a greater ability to learn new languages and about other cultures, communicate effectively and adapt to other cultures.

Sharma et al. (2009) propose that customers and employees with higher intercultural competence may feel more comfortable in intercultural service encounters because they are likely to understand and agree with each other's role to a greater extent compared to those with lower levels of intercultural competence. More recently, Sharma et al. (2012) show that intercultural competence positively moderates the negative impact of perceived cultural distance on interaction comfort. However, they do not explore its moderating impact on the effect of perceived cultural distance on perceived service quality. We argue that customers with higher intercultural competence are less likely to allow their perceived cultural distance with the service employees, to affect not only their interaction comfort but also perceived service quality, because both these constructs are essential elements of any intercultural service encounter. Therefore,

H7: The negative influence of perceived cultural distance on interaction comfort is stronger for customers with lower (vs. higher) intercultural competence.

H8: The negative influence of perceived cultural distance on perceived service quality is stronger for customers with lower (vs. higher) intercultural competence. 


\section{Consumer Ethnocentrism (CE)}

Consumer Ethnocentrism is defined as the "the beliefs held by consumers about the appropriateness, indeed morality, of purchasing foreign made products" (Shimp and Sharma, 1987). Prior research explores the influence of CE on the attitudes and behavioral intentions of consumers towards foreign products and service providers, showing a negative bias in their evaluation of foreign products and a positive bias in their preference for domestic products and services (Harrison-Walker, 1995). Customers with higher scores on ethnocentrism, patriotism, conservatism, and openness to foreign cultures are also more likely to have negative perceptions about imported products and services (Ali-Sulaiti and Baker, 1998; Sharma et al., 1995). In the intercultural service encounters context, Sharma (2005) show that consumer ethnocentrism has a negative effect on customers' expectations and perceptions about service employees from other cultures. However, there is hardly any other research that examines the effects of consumer ethnocentrism on interaction comfort or perceived service quality.

We argue that consumer ethnocentrism may work in quite the opposite manner as intercultural competence although they are not exactly opposite constructs. Specifically, due to their bias against service providers from other cultures, customers with higher ethnocentrism scores may not perceive a very high level of interaction comfort and service quality even if the service encounter has a successful outcome. In contrast, due to the absence of any bias against service providers from other cultures, customers with lower ethnocentrism scores may not perceive a very low level of interaction comfort and service quality even in case of service failures. Hence, we hypothesize as follows:

H9: The positive influence of service outcome on interaction comfort is stronger for customers with lower (vs. higher) consumer ethnocentrism. 
H10: The positive influence of service outcome on perceived service quality is stronger for customers with lower (vs. higher) consumer ethnocentrism.

Figure $1(\mathrm{H} 1-\mathrm{H} 10)$ summarizes all these hypotheses.

$<$ Insert Figures 1 about here $>$

\section{METHODOLOGY}

\section{Sample and Procedure}

We used a between-subjects 2 X 2 experimental design to manipulate service outcome (success vs. failure) and perceived cultural distance (low vs. high) with four versions of an intercultural service encounter scenario in a restaurant setting similar to recent research (e.g., Sharma et al., 2012). 204 university students in a major Australian city participated in this study. Table 1 summarizes the sample profile. We chose Australia for this study as it is rapidly becoming a multi-cultural society (Castles et al., 2013) and hence it is important to explore if the ethnic minorities still perceive unfriendliness, embarrassment, being ignored, lack of trust and unwillingness to interact with local service providers as reported in prior research (Barker and Härtel, 2004). Moreover, many frontline jobs in Australia are now held by ethnic minorities hence it would be useful to understand customer perceptions about the quality of service provided by an increasingly diverse workforce.

We used student participants as it helped us control for the influence of various demographic variables (e.g., age, education and occupation) and to ensure high response rate, both of which would have been difficult with participants from the general population. Moreover, the main purpose of our study is to explore the differences in the moderating impact of consumer ethnocentrism and inter-cultural competence and not to predict any specific behavior by the average consumer in the general population, hence the use of students is justified for an 
experimental study such as ours (Druckman and Kam, 2011). To minimize the possibility of demand effects and hypotheses guessing, we described this study as a consumer survey and debriefed all the participants sharing the real purpose and findings with them one month later.

We developed many versions of service failures and successes in diverse service categories ranging from on-campus library and fitness center to off-campus restaurant and medical clinic. We pre-tested all the scenarios with samples drawn from the same undergraduate population used in the main study, asking the participants to rank them on attributes including study realism, relevance, credibility and the extent of failure or success. We chose a restaurant setting with the two scenarios shown in Exhibit 1 and 2 that scored highest on all these attributes. $<$ Insert Exhibits $1 \& 2$ about here $>$

Participants were randomly assigned to one of the four conditions (low $\mathrm{PCD} /$ failure $=46$; low $\mathrm{PCD} /$ success $=57$; high $\mathrm{PCD} /$ failure $=58$; high $\mathrm{PCD} /$ success $=43$ ) and completed a structured questionnaire, which began with an intercultural service encounter scenario (success or failure) and asked the participants to imagine being in that situation. Next, they were shown photos of a Caucasian (low PCD) or a South-Asian (high PCD) waiter to manipulate perceived cultural distance, followed by a few questions. Both the photos were chosen based on a pretest with a different sample of students $(\mathrm{N}=50)$ from the same population used in the main study.

We tested the photos for attractiveness, likeability, believability and perceived cultural distance and picked those which allowed us to manipulate perceived cultural distance while controlling for all the other factors. We used both the photos in a randomized manner to avoid any systematic bias. We also collected several demographic variables including age, gender, ethnicity, work experience (no. of years) and food service experience (yes/no) for all the 
participants and included these as covariates in our data analyses. We adapted the following well-established scales to measure all the constructs:

- Perceived cultural distance (PCD): Five items adapted from the perceived cultural distance scale used by Sharma et al. (2012), with a seven-point Likert response format.

- Interaction comfort (IC): Three items adapted from the consumer comfort scale (Spake et al., 2003), with a seven-point Semantic Differential response format.

- Perceived service quality (PSQ): Three items used in prior research to measure overall service quality in diverse service categories (e.g., Zeithaml et al., 1996), with a sevenpoint Semantic Differential response format.

- Satisfaction (SAT): Three items adapted from existing customer satisfaction scales (e.g., Brady et al., 2005; Seiders et al., 2005), with a seven-point Semantic Differential format

- Consumer Ethnocentrism (CE): Four items adapted from existing consumer ethnocentrism scales (e.g., Sharma, 2011), with a seven-point Likert response format.

- Intercultural Competence (ICC): Five items adapted from existing intercultural competence scale (Sharma et al., 2012), with a seven-point Likert response format.

\section{DATA ANALYSIS AND FINDINGS}

We began with an assessment of the psychometric properties of all the scales, using confirmatory factor analysis with AMOS 19. The measurement model shows an excellent fit $\left(\chi^{2}\right.$ $\left.=263.35, d f=212, \chi^{2} / d f=1.24, \mathrm{CFI}=.98, \mathrm{NFI}=.97, \mathrm{RMSEA}=.035, \mathrm{SRMR}=.046\right)$ with all the fit indices better than their cut-off values $(\mathrm{CFI}>.95, \mathrm{NFI}>.90, \mathrm{RMSEA}<.06, \mathrm{SRMR}<.08$, $\left.1 \leq \chi^{2} / d f \leq 3\right)$. All the factor loadings are higher than .60 with significant $(p<.001)$ t-values and no major cross-factor loadings (all less than .40 ). Table 1 shows the properties of all the scales.

$<$ Insert Table 1 about here $>$ 
All the parameter estimates $(\lambda)$ are significantly different from zero at the $5 \%$ level, showing a high degree of convergent validity; and none of the confidence intervals of the correlation coefficients for each pair of scales ( $\Phi$ estimates) includes 1.0 , showing discriminant validity (Anderson and Gerbing, 1988). As a further test of discriminant validity we constrained the estimated correlation parameters among all the factors to 1.0 and found the $\chi^{2}$ value for this constrained model $\left(\chi^{2}=438.63, d f=233\right)$ significantly higher $\left(\Delta \chi^{2}=175.28, \Delta d f=21\right)$ than the unconstrained model. Hence, none of the factors are perfectly correlated with each other, which provides further support for their discriminant validity (Anderson and Gerbing, 1988).

All the scales are reliable with construct reliabilities (.82 to .90) higher than .60 (Bagozzi and $\mathrm{Yi}, 1988)$. Average variance extracted for each construct (.62 to .76) is greater than .50 and higher than the square of its correlation with the other constructs, providing further evidence of convergent validity (Fornell and Larcker, 1981). Table 2 shows the correlations matrix with composite reliability, average variance extracted and descriptives for all the constructs.

$<$ Take in Table 2 about here $>$

Having established the reliability and validity of all the scales, we checked manipulations of perceived cultural distance and service outcome and found a significantly higher score $(\mathrm{F}=$ 378.84, $\mathrm{p}<.001)$ for PCD under the high PCD condition $(\mathrm{M}=5.88)$ compared to the low PCD condition $(\mathrm{M}=3.04)$, and a significantly higher score $(\mathrm{F}=252.69, \mathrm{p}<.001)$ for customer satisfaction for the success outcome $(M=5.53)$ compared to the failure outcome $(M=2.75)$ condition. Hence, both these manipulations seem to have worked as expected.

Next, we used structural equation modeling (SEM) approach to test all our hypotheses as it allows us to simultaneously test all the main and interaction effects in a single structural model, making it easier to present and interpret our results. We analyzed the structural model to test our 
first six hypotheses about the main effects. The model shows a good fit $\left(\chi^{2}=117.09, d f=73\right.$, $\left.\chi^{2} / d f=1.60, \mathrm{CFI}=.97, \mathrm{NFI}=.95, \mathrm{RMSEA}=.044, \mathrm{SRMR}=.056\right)$ with all the fit indices better than their cut-off values. All the path coefficients are also significant and in the expected direction. Service outcome has a positive influence on interaction comfort $(\beta=.31, \mathrm{p}<.001)$ and perceived service quality $(\beta=.44, \mathrm{p}<.001)$, hence $\mathrm{H} 1$ and $\mathrm{H} 2$ are supported. In contrast, perceived cultural distance has a negative influence on both interaction comfort $(\beta=-.25, \mathrm{p}<.01)$ and perceived service quality $(\beta=-.21, \mathrm{p}<.01)$ as expected, supporting H3 and H4. Finally, both interaction comfort $(\beta=.22, \mathrm{p}<.01)$ and perceived service quality $(\beta=.53, \mathrm{p}<.001)$ have positive effects on customer satisfaction, hence H5 and H6 are also supported.

To test our next four hypotheses (H7-H10) about the moderating effects of intercultural competence and consumer ethnocentrism, we included the four interaction terms between the independent (PCD and Outcome) and moderator variables (ICC and CET) respectively in our model. We found support for all the four hypotheses. Specifically, intercultural competence has a positive moderating effect on the influence of perceived cultural distance on both, interaction $\operatorname{comfort}(\beta=.13, \mathrm{p}<.05)$ and perceived service quality $(\beta=.17, \mathrm{p}<.05)$; whereas in contrast, consumer ethnocentrism has a negative moderating effect on the influence of service outcome on both, interaction comfort $(\beta=-.24, \mathrm{p}<.01)$ and perceived service quality $(\beta=-.19, \mathrm{p}<.01)$. Figure 2 shows all the ten hypotheses and these results. None of the covariates had any significant direct or indirect effect on any of the variables or relationships in our model. Hence, we do not discuss these variables any further in this paper.

$$
<\text { Insert Figure } 2 \text { about here }>
$$

Next, we analyzed our data using multivariate analysis of variance (MANOVA) with service outcome and perceived cultural distance as manipulated factors and interaction comfort 
and perceived service quality as outcome variables to test $\mathrm{H} 1-\mathrm{H} 4$. We also tested the interactions between the median-split scores for the two moderators, intercultural competence and consumer ethnocentrism, and the two manipulated variables, service outcome and PCD respectively, to test H7-H10. We found similar results as those using structural equation modeling approach.

First, the scores for interaction comfort $(\mathrm{M}=5.04$ vs. $3.06, \mathrm{~F}=113.82, \mathrm{p}<.001)$ and perceived service quality $(\mathrm{M}=5.61$ vs. $3.05, \mathrm{~F}=197.34, \mathrm{p}<.001)$ are significantly higher for service success compared to failure $(\mathrm{H} 1-\mathrm{H} 2)$. Next, the scores for interaction comfort $(\mathrm{M}=3.36$ vs. $4.69, \mathrm{~F}=26.95, \mathrm{p}<.001)$ and perceived service quality $(\mathrm{M}=3.74$ vs. $4.46, \mathrm{~F}=9.77, \mathrm{p}<.001)$ are significantly lower for higher (vs. lower) perceived cultural distance (H3-H4). Finally, the differences in the scores for interaction comfort $(\Delta \mathrm{M}=1.66$ vs. $0.47, \mathrm{~F}=15.92, \mathrm{p}<.001)$ and perceived service quality $(\Delta \mathrm{M}=1.42$ vs. $0.25, \mathrm{~F}=18.54, \mathrm{p}<.001)$ are significantly different between the low and high PCD conditions for customers with lower (vs. higher) intercultural competence (H7-H8). Similarly, we found a greater difference in the scores for interaction comfort $(\Delta \mathrm{M}=-2.46$ vs. $-1.41, \mathrm{~F}=13.10, \mathrm{p}<.001)$ and perceived service quality $(\Delta \mathrm{M}=-2.99$ vs. $-2.10, \mathrm{~F}=9.39, \mathrm{p}<.01)$ between failure and success for higher (vs. lower) CET (H9-H10).

\section{DISCUSSION AND CONTRIBUTIONS}

In this paper, we extend the growing research on intercultural service encounters with a comprehensive conceptual framework (Figure 1), which incorporates direct effects of service outcome and perceived cultural distance on interaction comfort and service quality as well as their indirect effects on customer satisfaction. We also hypothesize that consumer ethnocentrism would negatively moderate the influence of service outcome on interaction comfort and service quality; whereas intercultural competence would positively moderate the influence of perceived cultural distance on interaction comfort and service quality. 
We used an experimental approach to test all our hypotheses because it provides greater control on various external factors that may confound other research methods such as critical incidence technique and field survey. We used a between-subjects design with a sample of university students to manipulate service outcome and perceived cultural distance with four versions of a basic scenario based on an intercultural service encounter in a restaurant setting, similar to Sharma et al. (2012). We found support for all our hypotheses.

Prior research shows that perceived cultural distance has a negative impact on interaction comfort and satisfaction in intercultural service encounters (e.g., Sharma et al., 2012); however we show that perceived cultural distance also has a direct negative effect on perceived service quality, which then affects customer satisfaction in combination with interaction comfort. This finding shows that customers, who perceive a greater cultural distance from a service employee, not only feel less comfortable in their interaction with such an employee but also perceive poor service quality and feel less satisfied with such a service encounter. Unlike some prior studies that do not distinguish between interaction comfort and service quality (Paswan and Ganesh, 2005), we clarify that these two are distinct constructs, which are separately influenced by perceived cultural distance and in turn both these affect customer satisfaction.

In this paper, we also compare the influence of service outcome (failure vs. success) on interaction comfort and service quality to address an important gap in prior research on intercultural service encounters, which mostly focused on service failures (e.g., Hopkins et al., 2005; Sharma et al., 2012; Stauss and Mang, 1999). By directly manipulating service outcome, we are able to control for all other possible confounding factors and compare our results across service failure and success using the same setting, thus offering a comprehensive framework incorporating both service failure and success in intercultural service encounters. 
Next, we show that the influence of service outcome and perceived cultural distance on interaction comfort and perceived service quality is moderated in contrasting manners, by two distinct constructs, namely consumer ethnocentrism and intercultural competence. Specifically, we show that customers with high consumer ethnocentrism scores perceive lower levels of interaction comfort and service quality for the same service experience, compared to customers with lower ethnocentrism scores. This finding adds to the research on intercultural service encounters by introducing the consumer ethnocentrism construct and showing its ability to negatively bias customers' perceptions and judgments about their interactions with service employees from different cultural or ethnic background than their own.

While prior research has shown the moderating effect of intercultural competence on the influence of perceived cultural distance on interaction comfort and customer satisfaction, we show that this moderating effect also affects customer perceptions about service quality itself. Hence, it seems that customers with higher levels of intercultural competence may be relatively more tolerant and able to adjust their expectations in intercultural service encounters, which would explain their higher ratings of service quality provided by culturally distant employees. Thus, by combining and contrasting the influence of consumer ethnocentrism and intercultural competence, we are able to provide a more comprehensive picture of the biases in customer perceptions and evaluations underlying intercultural service encounters.

\section{MANAGERIAL IMPLICATIONS}

Besides the above conceptual contributions, our research also offers many useful managerial insights. First, it shows that it is not enough for service managers to study service failures and try to improve their performance through service recovery; instead, it is equally important to understand that customers may also have biased perceptions and evaluations even in 
successful service encounters. In other words, managers in service firms engaged in intercultural service encounters would find it useful to track not only service failures but also successful encounters, which they would normally ignore assuming that customers would not have any negative perceptions about such encounters.

To address this issue, service managers would first need to understand the underlying causes (e.g., consumer ethnocentrism) for customers' biased perceptions about service quality that may also distort their satisfaction judgments. They would then need to develop effective strategies to deal with these biased perceptions and evaluations. One such strategy could be to train their frontline service employees in recognizing the ethnocentric tendencies among their customers starting from their first interactions with them. This would help the employees to be more conscious in addressing the concerns and expectations of such customers in a manner that would reduce the impact of their ethnocentric characteristics on their perceptions and judgments.

We also show that intercultural competence plays an important role in intercultural service encounters by moderating the negative impact of perceived cultural distance. Therefore, service managers would be well advised to train their employees in identifying customers with lower levels of intercultural competence and deal with them more effectively. This may require a lot more patience and understanding from the service employees because they would also have to overcome their own ethnocentric and stereotypical attitudes towards customers from different cultural and ethnic backgrounds compared to their own.

Finally, we show that it is not enough to focus on service quality despite its popularity in the last few decades; instead it is also important to improve interaction comfort for the customers especially with culturally distant service employees and for those customers who have higher levels of consumer ethnocentrism and lower levels of intercultural competence. Therefore, 
managers in international and global service firms such as airlines, banks, hotels etc. should hire employees with lower levels of ethnocentrism and higher levels of intercultural competence so that they could identify and address various concerns and problems that may arise in intercultural service encounters due to language barriers, cultural misunderstandings etc.

\section{LIMITATIONS AND FUTURE RESEARCH}

Despite its useful conceptual contributions and managerial implications, our research has a few limitations that may be addressed in future research. First, we manipulate service outcome with only two conditions - failure and success - in a service recovery scenario, to compare the differences in their influence on customer perceptions and evaluations. However, many service encounters may be more complicated and consist of multiple instances of failure and success, which may lead to some ambiguity or ambivalence in customer perceptions. Future research may address this by measuring the level of failure or success as a continuous variable (say, degree of failure or success) and use it as a predictor of interaction comfort, service quality and satisfaction. We think this would help provide deeper insights about the influence of service outcome.

Second, in this study we tried to minimize the possibility of any confounding effects of external variables such as customer knowledge, past experience and any personal biases, by using an experimental design with imaginary service scenarios and university students as participants in a service recovery context in a restaurant. We realize that all these caveats may restrict the generalizability of our findings and hence, future research using other methodologies such as critical incidence technique or experience surveys with a broader cross-section of customers from all walks of life, in diverse service contexts besides restaurants including airtravel, hotel stay, holiday trip etc. and using a combination of generic and service recovery scenarios, would help further test the generalizability of our findings. 
Finally, in this research we included two situational factors as independent variables (i.e., service outcome and perceived cultural distance), two individual characteristics as moderators (i.e., consumer ethnocentrism and intercultural competence) and three outcomes (i.e., interaction comfort, service quality and customer satisfaction) as dependent variables. However, these variables are by no means exhaustive and there could be other relevant and important variables in the context of intercultural service encounters, such as inter-role congruence (Sharma et al., 2009, 2012) or goal compatibility (Bitner et al., 1994) that may affect the service customers and employees in a different manner. We believe this would be a worthy avenue for future research.

\section{REFERENCES}

Ali-Sulaiti, K.I. and Baker, M.J. (1998), "Country of Origin Effects: A Literature Review", Marketing Intelligence \& Planning, Vol. 16 No. 3, pp. 150-99.

Anderson, J.C. and Gerbing, D.W. (1988), "Structural Equation Modeling in Practice: A Review and Recommended Two Step Approach", Psychological Bulletin, Vol. 103 No. May, pp. 411-23.

Bagozzi, R.P. and Yi, Y. (1988), "On the Evaluation of Structural Equation Models", Journal of the Academy of Marketing Sciences, Vol. 16 No. 1, pp. 74- 84.

Barker, S. and Härtel, C.E.J. (2004), "Intercultural Service Encounters: An Exploratory Study of Customer Experiences", Cross Cultural Management, Vol. 11 No. 1, pp. 3-14.

Bitner, M.J., Booms, B.H. and Mohr, L.A. (1994), "Critical Service Encounters: The Employee's Viewpoint", Journal of Marketing, Vol. 58 No. October, pp. 95-106.

Brady, M.K., Knight, G.A., Cronin, J.J.J., Hult, G.T.M. and Keillor, B.D. (2005), "Removing the Contextual Lens: A Multinational, Multi-Setting Comparison of Service Evaluation Models", Journal of Retailing, Vol. 81 No. 3, pp. 215-30.

Castles, S., Hugo, G. and Vasta, E. (2013), "Rethinking Migration and Diversity in Australia: Introduction", Journal of Intercultural Studies, Vol. 34 No. 2, pp. 115-21.

Dabholkar, P.A., Shepherd, C.D. and Thorpe, D.I. (2000), "A Comprehensive Framework for Service Quality: An Investigation of Critical Conceptual and Measurement Issues through a Longitudinal Study", Journal of Retailing, Vol. 76 No. 2, pp. 139-73. 
De Matos, C.A., Fernandes, D.V.D.H., Leis, R.P. and Trez, G. (2011), "A Cross-Cultural Investigation of Customer Reactions to Service Failure and Recovery", Journal of International Consumer Marketing, Vol. 23 No. 3-4, pp. 211-28.

Dolen, W.V., Ruyter, K.D. and Lemmink, J. (2004), "An Empirical Assessment of the Influence of Customer Emotions and Contact Employee Performance on Encounter and Relationship Satisfaction", Journal of Business Research, Vol. 57 No. 4, pp. 437-44.

Druckman, J.N. and Kam, C.D. (eds.) 2011. Students as Experimental Participants: Cambridge University Press.

Etgar, M. and Fuchs, G. (2011), "Does Ethnic/Cultural Dissimilarity Affect Perceptions of Service Quality?", Services Marketing Quarterly, Vol. 32 No. 2, pp. 113-28.

Fornell, C. and Larcker, D.F. (1981), "Evaluating Structural Equation Models with Unobservable Variables and Measurement Error", Journal of Marketing Research, Vol. 18 No. Feb, pp. 39-50.

Friedman, V.J. and Antal, A.B. (2005), "Negotiating Reality: A Theory of Action Approach to Intercultural Competence", Management Learning, Vol. 36 No. 1, pp. 69-86.

Harrison-Walker, L.J. (1995), "The Relative Effects of National Stereotype and Advertising Information on the Selection of a Service Provider", Journal of Services Marketing, Vol. 9 No. 1, pp. 47-59.

Hopkins, S.A., Hopkins, W.E. and Hoffman, K.D. (2005), "Domestic Inter-Cultural Service Encounters: An Integrated Model", Managing Service Quality, Vol. 15 No. 4, pp. 329-43.

Javalgi, R.G. and Martin, C.L. (2007), "Internationalization of Services: Identifying the Building-Blocks for Future Research", Journal of Services Marketing, Vol. 21 No. 6, pp. $391-7$.

Kulik, C.T. and Holbrook, R.L.J. (2000), "Demographics in Service Encounters: Effects of Racial and Gender Congruence on Perceived Fairness", Social Justice Research, Vol. 13 No. 4, pp. 375-402.

Laufer, D. (2002), "Are Antecedents of Consumer Dissatisfaction and Consumer Attributions for Product Failures Universal?". In: Broniarczyk, S.M. and Nakamoto, K., eds. Advances in Consumer Research, Valdosta, GA. Association for Consumer Research, pp. 312-7.

Lustig, M.W. and Koester, J. (2006), Intercultural Competence: Interpersonal Communication across Cultures, Boston, MA, Pearson.

Martin, C.L. and Adams, S. (1999), "Behavioral Biases in the Service Encounter: Empowerment by Default?", Marketing Intelligence \& Planning, Vol. 17 No. 4, pp. 192-201.

Mccormick, A.E. and Kinloch, G.C. (1986), "Interracial Contact in the Customer-Clerk Situation", The Journal of Social Psychology, Vol. 126 No. 4, pp. 551-3. 
Mohr, L.A. and Bitner, M.J. (1995), "The Role of Employee Effort in Satisfaction with Service Transactions", Journal of Business Research, Vol. 32 No., pp. 239-52.

Oliver, R.L. (1997), Satisfaction: A Behavioral Perspective on the Consumer, New York, NY, McGraw-Hill.

Oliver, R.L., Rust, R.T. and Varki, S. (1997), "Customer Delight: Foundations, Findings, and Managerial Insight", Journal of Retailing, Vol. 73 No. 3, pp. 311-36.

Parasuraman, A., Zeithaml, V.A. and Berry, L.L. (1988), "Servqual: A Multiple-Item Scale for Measuring Consumer Perceptions of Service Quality", Journal of Retailing, Vol. 64 No. 1, pp. 12-37.

Paswan, A.K. and Ganesh, G. (2005), "Cross-Cultural Interaction Comfort and Service Evaluation", Journal of International Consumer Marketing, Vol. 18 No. 1/2, pp. 93-115.

Schneider, B. and Bowen, D.E. (1985), "Employee and Customer Perceptions of Service in Banks: Replication and Extension", Journal of Applied Psychology, Vol. 70 No. 3, pp. 423-33.

Seiders, K., Voss, G.B., Grewal, D. and Godfrey, A.L. (2005), "Do Satisfied Customers Buy More? Examining Moderating Influences in a Retailing Context", Journal of Marketing, Vol. 69 No. October, pp. 26-43.

Sharma, P. (2011), "Country-of-Origin Effects in Developed Vs. Emerging Markets: Exploring the Contrasting Roles of Materialism and Value-Consciousness", Journal of International Business Studies, Vol. 42 No. 2, pp. 285-306.

Sharma, P., Sivakumaran, B. and Marshall, R. (2005), "Deliberate Self-Indulgence Vs. Involuntary Loss of Self-Control: Exploring the Influence of Culture on Consumer Impulsiveness Trait", European Advances in Consumer Research, Vol. 7 No., pp. 593-4.

Sharma, P., Tam, J.L.M. and Kim, N. (2009), "Demystifying Intercultural Service Encounters: Toward a Comprehensive Conceptual Framework", Journal of Service Research, Vol. 12 No. 2, pp. 227-42.

Sharma, P., Tam, J.L.M. and Kim, N. (2012), "Intercultural Service Encounters (Icse) Framework: Extension and Empirical Validation", Journal of Services Marketing, Vol. 26 No. 7, pp. 521-34.

Sharma, S., Shimp, T.A. and Shin, J. (1995), "Consumer Ethnocentrism: A Test of Antecedents and Moderators", Journal of the Academy of Marketing Science, Vol. 23 No. 1, pp. 26-37.

Shimp, T.A. and Sharma, S. (1987), "Consumer Ethnocentrism: Construction and Validation of the Cetscale", Journal of Marketing Research, Vol. 24 No. August, pp. 280-9. 
Spake, D.F., Beatty, S.E., Brockman, B.K. and Crutchfield, T.N. (2003), "Consumer Comfort in Service Relationships: Measurement and Importance", Journal of Service Research, Vol. 5 No. 4, pp. 316-32.

Stauss, B. and Mang, P. (1999), "'Culture Shocks" in Inter-Cultural Service Encounters?", Journal of Services Marketing, Vol. 13 No. 4/5, pp. 329-46.

Tajfel, H., Billig, M., Bundy, R.P. and Flament, C. (1971), "Social Categorization and Intergroup Behaviour", European journal of social psychology, Vol. 2 No., pp. 149-78.

Teng, C.-C. (2011), "Commercial Hospitality in Restaurants and Tourist Accommodation: Perspectives from International Consumer Experience in Scotland", International Journal of Hospitality Management, Vol. 30 No. 4, pp. 866-74.

Thelen, S.T., Yoo, B. and Magnini, V.P. (2011), "An Examination of Consumer Sentiment toward Offshored Services", Journal of the Adademy of Marketing Science, Vol. 39 No. 2, pp. 270-89.

Triandis, H.C. (1994), Culture and Social Behavior, New York, NY, McGraw Hill.

Ueltschy, L.C., Laroche, M., Eggert, A. and Bindl, U. (2007), "Service Quality and Satisfaction: An International Comparison of Professional Services Perceptions", Journal of Services Marketing, Vol. 21 No. 6, pp. 410-23.

Wang, C.-Y. and Mattila, A.S. (2010), "A Grounded Theory Model of Service Providers' Stress, Emotion, and Coping During Intercultural Service Encounters", Managing Service Quality, Vol. 20 No. 4, pp. 328-42.

Wang, C.-Y. and Mattila, A.S. (2011), "A Cross-Cultural Comparison of Perceived Informational Fairness with Service Failure Explanations", Journal of Services Marketing, Vol. 25 No. 6, pp. 429-39.

Warden, C.A., Liu, T.-C. and Huang, C.-T. (2003), "Service Failures Away from Home: Benefits in Intercultural Service Encounters", International Journal of Service Industry Management, Vol. 14 No. 4, pp. 436-57.

Weiermair, K. (2000), "Tourists' Perceptions Towards and Satisfaction with Service Quality in the Cross-Cultural Service Encounter: Implications for Hospitality and Tourism Management", Managing Service Quality, Vol. 10 No. 6, pp. 397-409.

Zeithaml, V.A., Berry, L.L. and Parasuraman, A. (1996), "The Behavioral Consequences of Service Quality", Journal of Marketing, Vol. 60 No. 2, pp. 31-46. 
Figure 1 - Conceptual framework

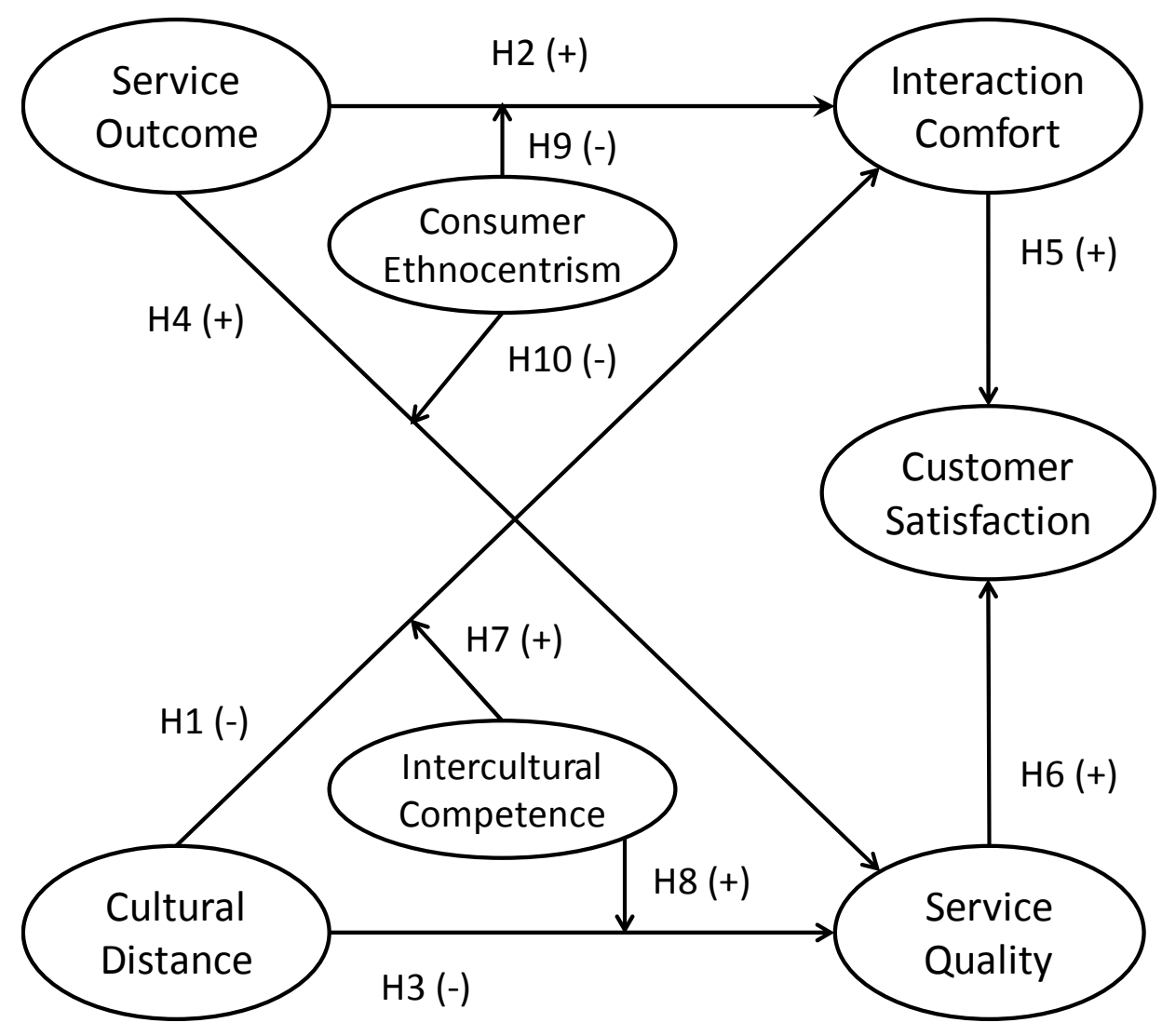


Figure 2 - Hypotheses and Results

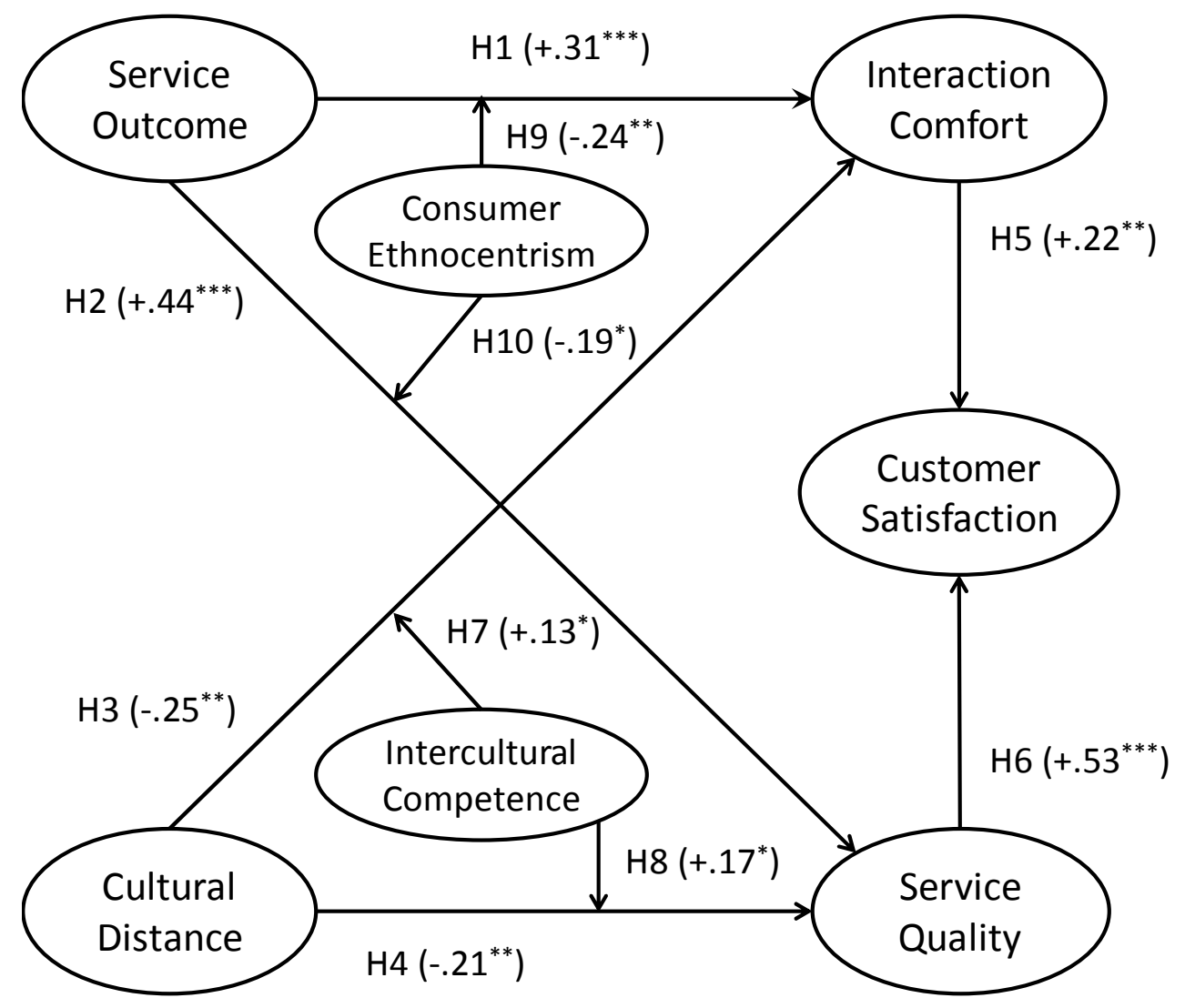


Table 1 - Sample Profile

\begin{tabular}{|c|c|c|c|c|c|}
\hline \multirow[b]{2}{*}{ Demographics } & \multirow[b]{2}{*}{$\begin{array}{l}\text { Overall } \\
(\mathrm{N}=\mathbf{2 0 4})\end{array}$} & \multicolumn{2}{|c|}{$\underline{\text { Low PCD }}$} & \multicolumn{2}{|c|}{ High PCD } \\
\hline & & $\begin{array}{l}\text { Failure } \\
(\mathrm{N}=46)\end{array}$ & $\begin{array}{l}\text { Success } \\
(\mathbf{N}=\mathbf{5 7})\end{array}$ & $\begin{array}{l}\text { Failure } \\
(\mathbf{N}=58)\end{array}$ & $\begin{array}{l}\text { Success } \\
(\mathrm{N}=43)\end{array}$ \\
\hline \multicolumn{6}{|l|}{ Gender } \\
\hline Female & $113(55 \%)$ & $18(39 \%)$ & $35(61 \%)$ & $31(53 \%)$ & $29(67 \%)$ \\
\hline Male & $91(45 \%)$ & $28(61 \%)$ & $22(39 \%)$ & $27(47 \%)$ & $14(33 \%)$ \\
\hline \multicolumn{6}{|l|}{ Age } \\
\hline$\leq 20$ & $79(39 \%)$ & $25(54 \%)$ & $21(37 \%)$ & $15(26 \%)$ & $18(42 \%)$ \\
\hline $21-30$ & $112(55 \%)$ & $15(33 \%)$ & $34(60 \%)$ & $38(66 \%)$ & $25(58 \%)$ \\
\hline $31-40$ & $9(4 \%)$ & $3(7 \%)$ & $2(4 \%)$ & $4(7 \%)$ & $0(0 \%)$ \\
\hline $41-50$ & $3(1.5 \%)$ & $3(7 \%)$ & $0(0 \%)$ & $0(0 \%)$ & $0(0 \%)$ \\
\hline$>50$ & $1(0.5 \%)$ & $0(0 \%)$ & $0(0 \%)$ & $1(2 \%)$ & $0(0 \%)$ \\
\hline \multicolumn{6}{|l|}{ Ethnicity } \\
\hline Chinese & $63(31 \%)$ & $6(13 \%)$ & $16(28 \%)$ & $25(43 \%)$ & $16(37 \%)$ \\
\hline Other Asian & $40(19 \%)$ & $11(24 \%)$ & $12(21 \%)$ & $8(14 \%)$ & $9(21 \%)$ \\
\hline Caucasian & $71(35 \%)$ & $23(50 \%)$ & $24(42 \%)$ & $11(19 \%)$ & $13(30 \%)$ \\
\hline Others & $30(15 \%)$ & $6(13 \%)$ & $5(9 \%)$ & $14(24 \%)$ & $5(12 \%)$ \\
\hline \multicolumn{6}{|c|}{ Work Experience } \\
\hline None & $19(9 \%)$ & $4(9 \%)$ & $7(12 \%)$ & $1(2 \%)$ & $7(16 \%)$ \\
\hline$<1$ year & $52(26 \%)$ & $7(15 \%)$ & $9(16 \%)$ & $24(41 \%)$ & $12(28 \%)$ \\
\hline $1-2$ years & $44(22 \%)$ & $9(20 \%)$ & $17(30 \%)$ & $11(19 \%)$ & $7(16 \%)$ \\
\hline $2-3$ years & $37(18 \%)$ & $8(17 \%)$ & $10(18 \%)$ & $14(24 \%)$ & $5(12 \%)$ \\
\hline $3-4$ years & $23(11 \%)$ & $8(17 \%)$ & $8(14 \%)$ & $3(5 \%)$ & $4(9 \%)$ \\
\hline$>4$ years & $29(14 \%)$ & $10(22 \%)$ & $6(11 \%)$ & $5(9 \%)$ & $8(19 \%)$ \\
\hline \multicolumn{6}{|c|}{ Food Service Experience } \\
\hline No & $94(46 \%)$ & $22(48 \%)$ & $27(47 \%)$ & $25(43 \%)$ & $20(47 \%)$ \\
\hline Yes & $110(54 \%)$ & $24(52 \%)$ & $30(53 \%)$ & $33(57 \%)$ & $23(53 \%)$ \\
\hline
\end{tabular}


Table 2 - Scale Summary $(\mathbf{N}=\mathbf{2 0 0})$

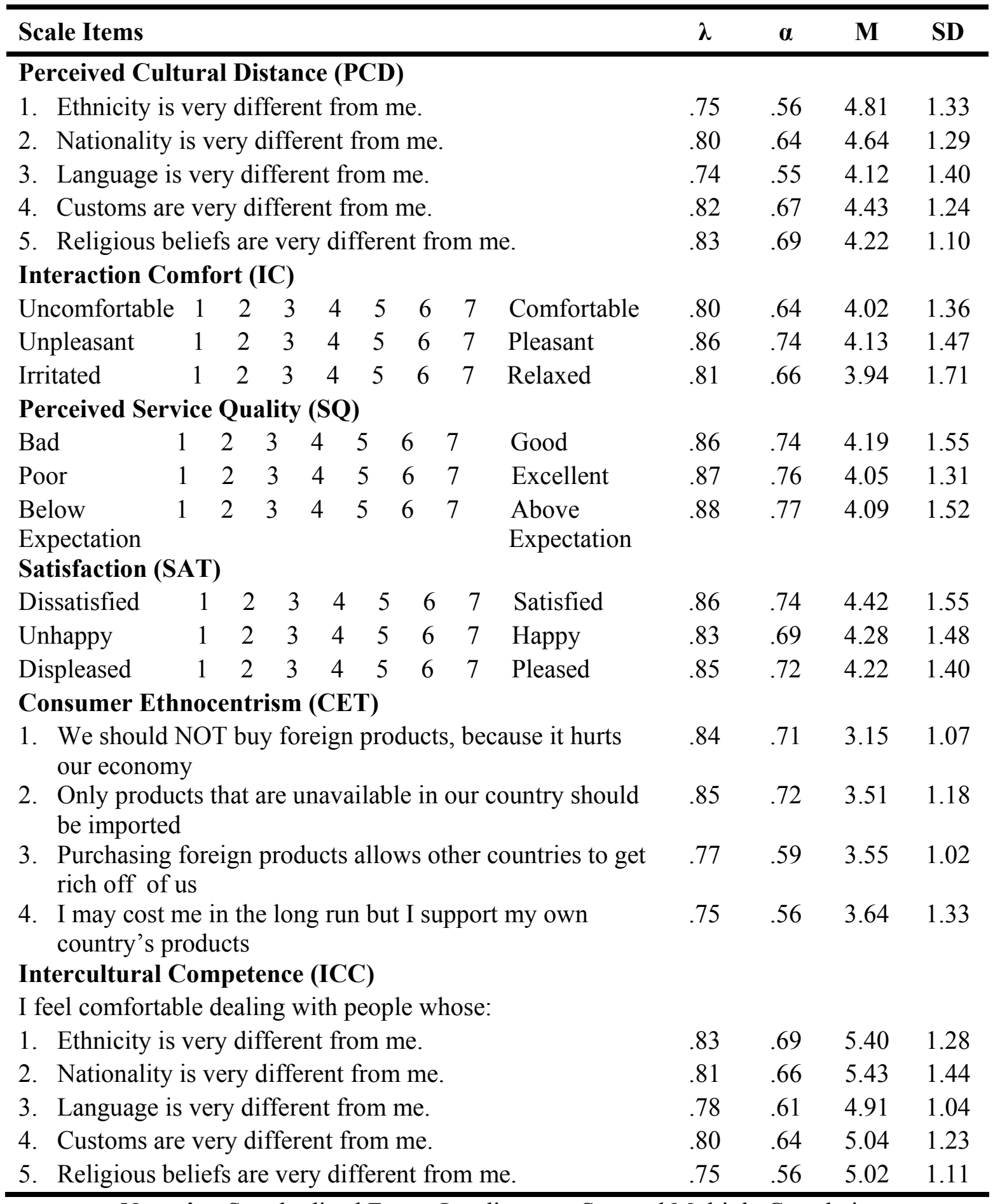

Note: $\lambda=$ Standardized Factor Loading; $\alpha=$ Squared Multiple Correlations;

$\mathrm{M}=$ Mean; $\mathrm{SD}=$ Standard Deviation 
Table 3 - Correlations Matrix $(\mathbf{N}=\mathbf{2 0 0})$

\begin{tabular}{lcccccccc}
\hline & PCD & IC & SQ & SAT & CET & ICC & Mean & SD \\
\hline $\begin{array}{l}\text { Perceived Cultural } \\
\text { Distance (PCD) }\end{array}$ & - & - & - & - & - & - & 4.44 & 1.24 \\
Interaction Comfort (IC) & $-.21^{* *}$ & - & - & - & - & - & 4.03 & 1.53 \\
$\begin{array}{l}\text { Perceived Service } \\
\text { Quality (SQ) }\end{array}$ & $-.16^{*}$ & $.33^{* * *}$ & - & - & - & - & 4.11 & 1.41 \\
Satisfaction (SAT) & $-.10^{*}$ & $.37^{* * *}$ & $.43^{* * *}$ & - & - & - & 4.31 & 1.44 \\
$\begin{array}{l}\text { Consumer } \\
\text { Ethnocentrism (CET) }\end{array}$ & $.14^{*}$ & -.04 & -.03 & $-.09^{*}$ & - & - & 3.46 & 1.17 \\
$\begin{array}{l}\text { Intercultural } \\
\text { Competence (ICC) }\end{array}$ & $-.31^{* * *}$ & $-.10^{*}$ & -.02 & -.03 & $-.26^{* * *}$ & - & 5.16 & 1.28 \\
\hline $\begin{array}{l}\text { Composite Reliability } \\
\text { (CR) }\end{array}$ & .82 & .85 & .92 & .88 & .84 & .83 & - & - \\
$\begin{array}{l}\text { Average Variance } \\
\text { Extracted (AVE) }\end{array}$ & .62 & .68 & .76 & .72 & .65 & .63 & - & - \\
\hline
\end{tabular}




\section{Exhibit 1 - Service Failure Scenario}

"One day it is a busy evening at a popular restaurant when a customer walks in without a booking and asks the nearest waiter to find a table. The waiter requests the customer to wait for a while but being in a hurry, the customer insists on getting a table immediately. However, there are no vacant tables and the customer has to wait for almost $\mathbf{1 5}$ minutes, before being seated. The customer is not very familiar with the menu and takes a long time to decide. All this time, the waiter stands next to the customer waiting to take the order. Being a busy evening, the food arrives after almost 30 minutes and all this time, the customer keeps calling the waiter to find out about the order. After the food is served, the customer says that it is the wrong order and refuses to eat the food or pay the bill. The waiter argues with the customer to prove that the food is exactly as per the order. However, the customer insists that it is the wrong order and asks to see the manager and for the complaint-book to make a formal complaint."

\section{Exhibit 2 - Service Success Scenario}

"One day it is a busy evening at a popular restaurant when a customer walks in without a booking and asks the nearest waiter to find a table. The waiter requests the customer to wait for a while but being in a hurry, the customer insists on getting a table immediately. The waiter manages to find a vacant table and the customer has to wait only for a few minutes before being seated. The customer is not very familiar with the menu and takes a long time to decide. All this time, the waiter stands next to the customer waiting to take the order and makes many useful suggestions. Despite being a busy evening, the food arrives within a few minutes and all this time, the waiter stays close to the customer keeping him informed about the order. After the food is served, the customer finds that it is the wrong order and tells the waiter. The waiter apologizes for the mistake and promptly replaces it with the correct order besides offering a free bottle of wine to the customer."

Note: The text in bold shows the difference between the two scenarios used to manipulate the service outcome (failure vs. success). 